If liquorice or its derivatives stimulated the adrenal to produce aldosterone, or inhibited aldosterone metabolism, a rise in aldosterone excretion would be expected. If liquorice or derivatives have aldosterone-like action aldosterone excretion will be suppressed. The published results in man for liquorice and glycyrrhizinic acid are consistent; there is normal or reduced aldosterone excretion (Mollaret, Goulon, and Tournilhac, 1960 ; Drosdowski, Robel, and Sebaoun, 1961 ; Garcin, Goulon, Tournilhac, and Amor, 1961 ; Jenny, Muller, Fabre, and Mach, 1961 ; Salassa, Mattox, and Rosevear, 1962 ; Minivielle, Cristol, and Badach, 1963 ; Conn, Rovner, and Cohen, 1968) and secretion (Jenny et al., 1961 ; Conn et al., 1968). Plasma renin activity is also suppressed (Conn et al., 1968). These changes are reversible on stopping the liquorice preparations and can be produced again by restarting them.

The results reported here with carbenoxolone, a glycyrrhetinic acid salt, as well as the reports with glycyrrhizinic acid or liquorice, are consistent only with the hypothesis that the mireralocorticoid effect of carbenoxolone is due to its possessing intrinsic aldosterone-like properties. The unchanged morning plasma renin activity after carbenoxolone would suggest that the suppression of aldosterone secretion by carbenoxolone is not renin-mediated. It is most unlikely that a change in A.C.T.H. secretion was responsible for this fall in aldosterone secretion, since liquorice and its derivatives have little or no glucocorticoid activity (Baron and Nabarro, 1968, p. 150). We therefore suggest that this fall in aldosterone secretion is related to the fall in plasma potassium concentration (Laragh and Stoerk, 1957). Since we did not observe any change in external potassium balance our results suggest that aldosterone secietion is related to potassium concentration outside cells rather than inside cells.

The side-effects of carbenoxolone can be related to its mineralocorticoid effect and can be prevented by simultaneous administration of spironolactone, though at the cost of loss of therapeutic effect of ulcer-healing (Doll, Langman, and Shawdon, 1968). The side-effects could also be lessened by the diuretic hydrochlorothiazide without loss of ulcer-healing effect but at the expense of potassium depletion (Doll et al., 1968), and it is likely that a restricted sodium intake would prevent side-effects of carbenoxolone without loss of healing powers and without potassium depletion.

We are indebted to the patient for permitting us to make these studies. We wish to thank Miss McLaughlin, chief dietitian, Middlesex Hospital, for the balance diet; Sister Barnard for care of the patient; Mrs. M. Payne and Miss P. Batters for their assistance; and Dr. Miller, of the Courtauld Institute of Biochemistry, for the routine blood tests. The support by the Wellcome Trust of J.H.B. and J.D.H.S. is gratefully acknowledged.

\section{REFERENCES}

Baron, J. H., and Nabarro, J. D. N. (1968). In Symposium on Carbenoxolone Sodium, edited by J. M. Robson and F. M. Sullivan, p. 127. London, Butterworths.

Conn, J. W., Rovner, D. R., and Cohen, E. L. (1968). Fournal of the American Medical Association, 205, 492. Doll, R., Langman, M. J. S., and Shawdon, H. H. (1968). Gut, 9, 42.
Drosdowski, M., Robel, P., and Sebaoun, J. (1961). Presse Médicale, 69,

Garcin, R., Goulon, M., Tournilhac, M., and Amor, B. (1961). Revue Neurologique, 104, 461.

Jenny, M., Muller, A. F., Fabre, J., and Mach, R. S. (1961). Schweizerische medizinische Wochenschrift, 91, 869 .

Laragh, J. H., and Stoerk, H. C. (1957). fournal of Clinical Investigation, 36, 383 .

Minivielle, J., Cristol, P., and Badach, L. (1963). Presse Médicale, 71, 2021 .

Mollaret, P., Goulon, M., and Tournilhac, M. (1960). Bulletins et Mémoirs de la Société Médicale des Hôpitaux de Paris, 76, 491.

Salassa, R. M., Mattox, V. R., and Rosevear, J. W. (1962). Fournal of Clinical Endocrinology and Metabolism, 22, 1156.

Slater, J. D. H., et al. (1969). Clinical Science. In press.

Tuffley, R. E., and Slater, J. D. H. (1969). In preparation.

\title{
Blood Platelet Behaviour During and After Open-heart Surgery
}

\author{
F. N. MCKENZIE,* M.B.; \\ D. P. DHALL, $\dagger$ M.B., PH.D., F.R.C.S.ED.; K.-E. ARFORS, $\ddagger$ PH.D. \\ S. NORDLUND, $\S$ M.D. ; N. A. MATHESON,\| CH.M., F.R.C.S., F.R.C.S.ED.
}

British Medical fournal, 1969, 2, 795-798

\begin{abstract}
Summary : In view of the high incidence of thromboembolic complications after the insertion of cardiac vaive prostheses, platelet adhesiveness and aggregation was measured in whole blood before, during, and for several days after this operation in 10 patients. Cardiopulmonary bypass resulted in a profound decrease in the platelet count, in the number of adhesive platelets, and in platelet aggregation. These changes returned to near preoperative levels by the sixth postoperative day. Thereafter a consistent and sustained increase in platelet count, in the number of adhesive platelets, and in platelet aggregation was observed. The results suggest that the prevalence of thromboembolism after valve replacement may be due partly to changes in platelet behaviour.

* House Surgeon, Royal Infirmary, Aberdeen.

$\dagger$ Registrar, Royal Infirmary, Aberdeen. $\$$ Department of Clinical Physiology, Academic Hospital, Uppsala,

5 Department of Surgery, Norrkoping, Sweden.

II Consultant Surgeon, Royal Infirmary, Aberdeen.
\end{abstract}

The operative mortality of acquired cardiac valvular disease has fallen in recent years. Nevertheless, several detailed follow-up studies have shown an alarming incidence of both fatal and non-fatal postoperative arterial thromboembolic complications (Table I). From these studies it is clear that thromboembolic complications comprise the most important factor responsible for the delayed mortality and morbidity after heart valve replacement.

The role of platelets in thrombosis has been recognized for many years, and abnormalities in platelet behaviour have been shown to follow surgical operations (Wright, 1942 ; Emmons and Mitchell, 1965 ; Hampton and Mitchell, 1966 ; Bennett, 1967). Bygdeman et al. (1966) suggested that there is a correlation between the degree of increase in platelet adhesiveness and the subsequent development of venous thrombosis in surgical patients. Since patients undergoing open-heart surgery are exposed to a high risk of thromboembolic complications it appeared to be of value to examine their platelet response. 


\section{Material and Methods}

In the 10 patients studied (Table II) extracorporeal circulation was maintained with a PEMCO disc oxygenator, at high flow rates $(>2 \cdot 21 . /$ sq. m.). The machine was primed with equal volumes of balanced salt solution (Salidex) and 1-day-old A.C.D. (citric acid, trisodium citrate, dextrose) blood to which

TABLE 1.--Incidence of Thromboembolic Episodes Found in Four

\begin{tabular}{|c|c|c|c|c|}
\hline \multirow[b]{2}{*}{ Series } & \multicolumn{2}{|c|}{ Aortic Valve Replacement } & \multicolumn{2}{|c|}{ Mitral Valve Replacement } \\
\hline & $\begin{array}{l}\text { No. of } \\
\text { Cases }\end{array}$ & $\begin{array}{c}\text { No. of } \\
\text { Thromboembolic } \\
\text { Episodes }\end{array}$ & $\begin{array}{l}\text { No. of } \\
\text { Cases }\end{array}$ & $\begin{array}{c}\text { No. of } \\
\text { Thromboembolic } \\
\text { Episodes }\end{array}$ \\
\hline $\begin{array}{l}\text { Effler et al. (1965) } \\
\text { Herr et al. (1965) } \\
\text { Duvoisin et al. }(1967) \\
\text { Akbarian et al. (1968) }\end{array}$ & $\begin{array}{r}117 \\
90 \\
221 \\
155\end{array}$ & $\begin{array}{r}5 \\
12 \\
69 \\
39\end{array}$ & $\begin{array}{r}83 \\
65 \\
166 \\
80\end{array}$ & $\begin{array}{l}22 \\
27 \\
54 \\
18\end{array}$ \\
\hline Total & 583 & $125(21 \%)$ & 394 & $121(29 \cdot 6 \%)$ \\
\hline
\end{tabular}

$20 \mathrm{mg}$. of heparin per $400 \mathrm{ml}$. was added. Then $500 \mathrm{ml}$. of $20 \%$ albumin solution (Kabi) was added to the priming fluid. Moderate hypothermia (lowest oesophageal temperature $28-29^{\circ}$ C.) was induced during the period of bypass. Oral anticoagulant therapy with dicoumarol was started on the second or third day after operation in the eight patients in whom a prosthesis had been inserted.

\begin{tabular}{|c|c|c|c|c|c|}
\hline $\begin{array}{l}\text { Case } \\
\text { No. }\end{array}$ & Age & Sex & Diagnosis & $\begin{array}{c}\text { Total } \\
\text { Bypass Time } \\
\text { (Minutes) }\end{array}$ & $\begin{array}{c}\text { Valve } \\
\text { Inserted or } \\
\text { Operation }\end{array}$ \\
\hline $\begin{array}{l}1 \\
2 \\
3 \\
4 \\
5 \\
6 \\
7 \\
8\end{array}$ & $\begin{array}{l}45 \\
51 \\
45 \\
44 \\
54 \\
49 \\
58 \\
54\end{array}$ & $\begin{array}{c}\mathbf{M} \\
\mathbf{M} \\
\mathbf{F} \\
\mathbf{F} \\
\mathbf{F} \\
\mathbf{M} \\
\mathbf{M}\end{array}$ & $\begin{array}{l}\text { M.S. + M.R. } \\
\text { A.S. } \\
\text { M.S. } \\
\text { M.S. } \\
\text { M.S. + M.R. } \\
\text { A.S. + A.R. } \\
\text { M.S. + M.R. } \\
\text { A.R. + M.R. }\end{array}$ & $\begin{array}{r}93 \\
130 \\
81 \\
22 \\
93 \\
127 \\
32 \\
179\end{array}$ & $\begin{array}{l}\text { Cutter No. } 9 \\
\text { Starr-Edwards } 11 \text { A } \\
\text { Cutter No. } 9 \\
\text { Commissurotomy } \\
\text { Cutter No. } 9 \\
\text { Cutter No. } 4 \\
\text { Commissurotomy } \\
\text { Cutter No. } 4 \text { (aortic). }\end{array}$ \\
\hline 9 & 28 & $\mathbf{M}$ & A. $R$. & 94 & $\begin{array}{l}\text { Teflon covered Starr- } \\
\text { Edwards }\end{array}$ \\
\hline 10 & 37 & F & A.S.D. + M.R. & 81 & $\begin{array}{l}\text { Dacron patch; valvulo- } \\
\text { plasty }\end{array}$ \\
\hline
\end{tabular}

A.S. $=$ Aortic stenosis $\quad$ A.R. $=$ Aortic regurgitation. M.S. $=$ Mitral stenosis M.R. = Mitral regurgitation. A.S.D. = Atrial septal defect.

Blood was obtained by atraumatic venepuncture with widebore (SG 20) siliconized stainless-steel needles and plastic syringes. Nine millilitres of blood was gently mixed with $1 \mathrm{ml}$. of $3.13 \%$ trisodium citrate dihydrate in a plastic test-tube. Precisely 15 minutes after venepuncture platelet adhesiveness was measured in whole blood according to the glass-beadcolumn method of Hellem (1960). Two millilitres of blood was passed at a constant speed through a plastic tube containing $2.5 \mathrm{~g}$. of glass beads (Ballotini No. 8). Platelets in whole blood were counted in duplicate according to the method of Brecher and Cronkite (1950) before and after their passage through the glass-bead column. The difference in the two counts represents the number of platelets lost by adhesion to the glass beads. The result may also be expressed as percentage adhesive platelets by dividing the number of adhesive platelets by the initial platelet count.

Platelet aggregation in whole blood was measured by the platelet aggregate filtration pressure method of Dhall and Matheson (1969). Briefly, this method consists of measuring the pressure developed by the passage of whole blood-to which adenosine diphosphate (A.D.P.) has been added-through a standard microfilter with pores $20 \mu$ square. This pressure depends on the size of platelet aggregates induced by A.D.P. To 2-ml. aliquots of citrated blood, $5 \mu 1$. of A.D.P. was added to give a final concentration of $0.5 \mu \mathrm{g} . / \mathrm{ml}$. The A.D.P. was mixed by inverting the tube 12 times in 15 seconds. Fifty-five seconds after the addition of A.D.P. $1.26 \mathrm{ml}$. of blood was filtered, and the maximal pressure developed at the end of 10 seconds was measured with a strain gauge. Three measure- ments were made with each sample and the result was expressea as the mean. Allowance may be made for alterations in the platelet count by expressing the platelet aggregate filtration pressure per $10^{5}$ platelets. In view of the wide range of these values found in health, each subject in this study was used as his or her own control.

Packed cell volume was measured in duplicate by means of an international microhaematocrit centrifuge. All glassware used was siliconized (Siliclad, Clay-Adams).

Control observations were made on venous blood on the day before operation. Three arterial samples were obtained during the operation-the first after the administration of heparin $(3 \mathrm{mg} . / \mathrm{kg}$.) but before the institution of cardiopulmonary bypass, the second from the arterial side of the heart-lung machine after 30 to 40 minutes of perfusion, and the third at the end of the operation after the administration of protamine ( $4 \mathrm{mg} . / \mathrm{kg}$.). Further venous samples were examined on the third, sixth, tenth, and thirteenth days after operation and in seven patients on the seventeenth and the twentieth day after operation.

\section{Results}

Platelet Count (Fig. 1).-The mean preoperative plateint count was $188,000 / \mathrm{cu}$. mm., with a range of 132,000 to 268,000 / $\mathrm{cu} . \mathrm{mm}$. There was a slight but highly significant reduction in the platelet count during thoracotomy $(\mathbf{P}<0.001)$ followed by a precipitous fall within the first 30 to 40 minutes of cardicpulmonary bypass $(57 \%, \mathrm{P}<0.001)$. The magnitude of reduction in platelet count was found to be independent of the length of perfusion, but seemed to be related to the initial platelet count $(r=0.63, P=0.05)$. A further slight but insignificant decrease was observed on the third day after operation, but by the sixth day the mean platelet count had almost returned to preoperative levels. Thereafter, a marked and sustained thrombocytosis occurred, the platelet count reaching a peak of $130 \%$ above the preoperative value on the thirteenth day after operation $(P<0.01)$. The mean platelet count was still $80 \%$ above the preoperative level on the twentieth day after operation, but the wide variation between individuals reduces the significance of this observation.

Number of Adhesive Platelets and Percentage Adhesiveness (Figs. 1 and 2).-Despite the decrease in platelet count during thoracotomy, the number of adhesive platelets was not signi-

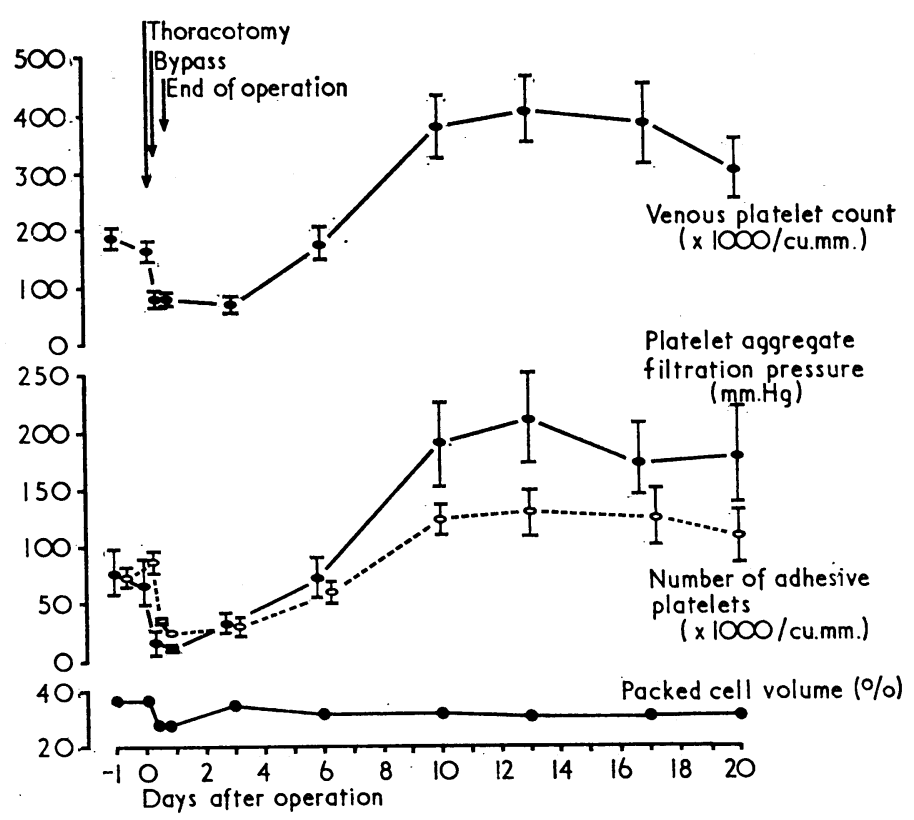

FIG. 1.-Platelet count, platelet aggregate filtration pressure (PAFP), and number of adhesive platelets (mean values \pm standard error of mean). 
ficantly altered. Nevertheless, a rapid decrease was observed in the number of adhesive platelets during the initial stages of cardiopulmonary bypass, and a highly significant reduction persisted until the third postoperative day $(\mathbf{P}<0.001)$. This was followed by a progressive increase in the number of adhesive platelets to reach a maximum on the thirteenth postoperative day $(P<0.05)$. Though a large increase in the mean number of adhesive platelets ( $40 \%$ above the preoperative level) was found on the twentieth day, the individual variation again reduced the significance of this finding. A slight but scarcely significant increase in the percentage of adhesive platelets was found during thoracotomy $(P<0.02)$. During cardiopulmonary bypass a small statistically insignificant diminution was found and percentage platelet adhesiveness had decreased to preoperative levels by the end of operation. Thereafter small fluctuations in the percentage of adhesive platelets were observed without any characteristic trend.

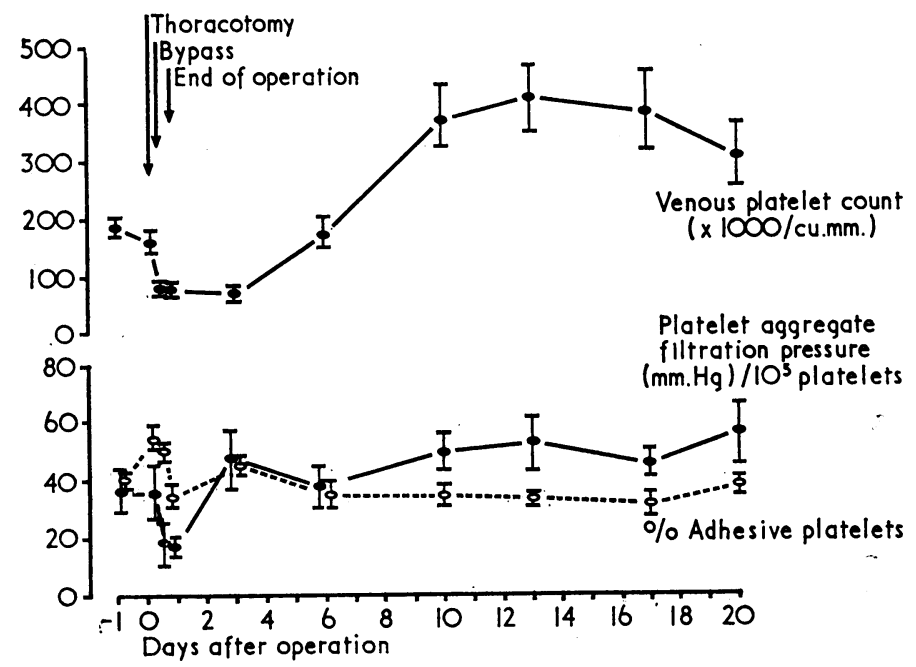

FIG. 2.-Platelet count, PAFP per $10^{5}$ platelets, and percentage adhesive platelets (mean values \pm standard error of mean).

Platelet Aggregate Filtration Pressure (Fig. 1).-Platelet aggregation in response to added A.D.P. decreased slightly during thoracotomy and profoundly during cardiopulmonary bypass; a highly significant reduction was maintained until the third postoperative day $(P<0 \cdot 001)$. Thereafter platelet aggregation increased, reaching preoperative levels by the sixth day and maximal values on the thirteenth day, after which it declined.

Fig. 2 shows the platelet aggregate filtration pressure expressed per unit number of platelets to allow for the influence of changes in the platelet count. A significant reduction in platelet aggregation $(\mathrm{P}<0.01)$ was observed during bypass and at the end of operation, but by the third day platelet reactivity to A.D.P. had returned to initial values and thereafter did not change significantly up to the twentieth day.

Packed Cell Volume.-This was reduced from 36 to $27 \%$ during the bypass, a fall explained by the dilution of the patient's blood with the red-cell-poor priming fluid. A return to the control value was observed by the third day, and thereafter the packed cell volume decreased to about $31 \%$, where it remained for the duration of the observations.

\section{Discussion}

Thromboembolic complications are a particular hazard of acquired valvular disease, especially when the mitral valve is involved (Olesen, 1955 ; Ellis et al., 1959 ; Loogen and Seipel, 1967). Relative stasis of blood in an enlarged and fibrillating left atrium and turbulence of blood flow across a narrow and distorted valve are possible factors underlying this risk. Despite a partial surgical correction of the haemodynamic defect by the insertion of a prosthetic valve, the reported findings (Table I) show that the patient remains at risk. A similar incidence of serious thromboembolic complications was found in a retrospective study of 54 patients who underwent mitral valve replacement between 1961 and 1967 in Uppsala, Sweden. Thromboembolism had either been a direct cause or had significantly contributed to death in $15(28 \%)$ of these 54 patients.

Though general surgical operations are known to be followed by altered platelet behaviour, there is a lack of similar information in patients undergoing open-heart surgery. The present investigation has shown that a consistent pattern of platelet response occurs in such patients. A pronounced decrease in the platelet count, in the number of adhesive platelets, and in the aggregation of platelets in response to A.D.P. occurs rapidly after the institution of cardiopulmonary bypass. A further slight reduction in the platelet count is seen on the third day after operation. Nevertheless, both platelet aggregation in response to A.D.P. and the number of adhesive platelets are increased despite the further fall in the platelet count at this time. This is followed by a pronounced and sustained increase in the platelet count accompanied by an equally pronounced increase both in the number of adhesive platelets and in platelet aggregation in response to A.D.P.

A decrease in platelet count during cardiopulmonary bypass is well documented (Kendall and Lowenstein, 1962). The decrease is in excess of the reduction due to dilution alone. Platelet loss by destruction (Bernstein et al., 1967), by adhesion to components of the extracorporeal system (Sharp et al., 1961), by heparinization (Gollub and Ulin, 1962), and by platelet sequestration (Ashmore et al., 1968) have been suggested as possible aetiological factors. A further slight decrease in the platelet count on the third day after operation confirms the findings of Crafoord et al. (1957) and DeWall et al. (1959), and may indicate continuing utilization of platelets in the presence of megakaryocytic immaturity.

Previous work has shown that operation is followed by an increase both in the platelet count and in the platelet adhesiveness (Wright, 1942 ; Bennett, 1967 ; Ham and Slack, 1967). In the present study open-heart surgery was followed by a somewhat different platelet response consisting of a striking increase in the platelet count, in the number of adhesive platelets, and in platelet aggregation. These pronounced changes are, however, attributable to the increase in circulating platelet mass, since adhesiveness and aggregation when expressed per unit number of platelets were relatively unchanged. It is possible that the duration and magnitude of the thrombocytosis mask changes in the behaviour of the individual platelet. Nevertheless, the enormous increase in the total platelet count and in the absolute number of reactive platelets sets the scene for the initiation of thrombosis. Thus, apart from the thrombogenetic potential associated with the implantation of intracardiac prostheses (Mirkovitch et al., 1960), the prevalence of thromboembolism after valve replacement may be partly attributable to changes in platelet behaviour after open-heart surgery.

The use of prophylactic oral anticoagulant therapy after valve replacement remains controversial. In some centres (Duvoisin et al., 1967 ; Yeh et al., 1967 ; Akbarian et al., 1968) it is routinely used after surgery in the absence of specific contraindications; in others (Cooley et al., 1964) anticoagulants are omitted in selected patients; while at others (Effler et al., 1965) its use is considered unjustified because of the difficulty in maintaining adequate dosage and the risks of complications. Furthermore, oral anticoagulants have no demonstrable effect on platelet reactivity (Murphy et al., 1963), and their use probably does not suppress thrombosis at the time of its inception. Thus a careful evaluation of materials known to influence platelet behaviour may be of value in patients undergoing valve replacement surgery. 
The assistance of Pharmacia A.B., Uppsala, Sweden, and the co-operation of the staff of the department of thoracic surgery, Academic Hospital, Uppsala, Sweden, are gratefully acknowledged. Our thanks are also due to $\mathrm{Mr}$. D. Hall for statistical advice.

\section{REFERENCES}

Akbarian M., Austen, W. G., Yurchak, P. M., and Scannell, J. G. (1968), Circulation, 37, 826.

Ashmore, P. G., Svitek, V., and Ambrose, P. (1968). Fournal of Thoracic and Cardiovascular Surgery, 55, 691 .

Bennett, P. N. (1967). Fournal of Clinical Pathology, 20, 708.

Bernstein, E. F., Indeglia, R. A., Shea, M. A., and Varco, R. L. (1967). Circulation, 35, Suppl. No. 1, p. 226

Brecher, G., and Cronkite, E. P. (1950). Fournal of Applied Physiology, 3, 365 .

Bygdeman, S., Eliasson, R., and Johnson, S.-R. (1966). Lancet, 1, 1301. Cooley, D. A., Nelson, T. G., Beall, A. C., jun., and DeBakey, M. E. (1964). Diseases of the Çhest, 46, 339 .

Crafoord, C., Norberg, B., and Senning, \&. (1957). Acta Chirurgica Scandinavica, 112, 220 .

DeWall, R. A., Long, D. M., Gemmill, S. J., and Lillehei, C. W. (1959). fournal of Thoracic Surgery, 37, 325 .

Dhall, D. P., and Matheson, N. A. (1969). Circulation Research, 3, 155.

Dhall, D. P., and Matheson, N. A. (1969). Circulation Research, 3, 155.
Duvoisin, G. E., Brandenburg, R. O., and McGoon, D. C. (1967). Circulation, 35, Suppl. No. 1, p. 70 .
Effler, D. B., Favaloro, R., and Groves, L. K. (1965). Annals of Thoracic

Surgery, 1, 4.
Ellis, L. B., Harken, D. E., and Black, H. (1959). Circulation, 19, 803. Emmons, P. R., and Mitchell, J. R. A. (1965). Lancet, 1, 71 .

Gollub, S., and Ulin. A. W. (1962). fournal of Laboratory and Clinical Medicine, 59, 430 .

Ham, J. M., and Slack, W. W. (1967). British fournal of Surgery, 54, 385.

Hampton, J. R., and Mitchell, J. R. A. (1966). British Medical fournal, 1, 1078 .

Hellem, A. J. (1960). Scandinavian Fournal of Clinical and Laboratory Investigation, 12, Suppl. p. 51.

Herr, R., Starr. A., McCord, C. W., and Wood, J. A. (1965). Annals of Thoracic Surgery, 1, 403.

Kendall, A. G., and Lowenstein, L. (1962). Canadian Medical Association fournal, 87, 786.

Loogen, F., and Seipel, L. (1967). Deutsche medizinische Wochenschrift, 92, 1.,

Mirkovitch, V., Akutsu, T., and Kolff, W. J. (1960). Physiologist, 3, 114.

Murphy, E. A., Mustard, J. F., Rowsell, H. G., and Downie, H. G. (1963). Gournal of Laboratory and Clinical Medicine, 61, 935.

Olesen, K. H. (1955). Mitral Stenosis: A Follow-up of 351 Patients. Copenhagen, Munksgaard.

Sharp, A. A., Excell, B., Salzman, E., and Thorup, O. (1961). In Thrombosis and Anticoagulant Therapy, edited by W. Walker, p. 88. Edinburgh, Livingstone.

Wright, H. P. (1942). Fournal of Pathology and Bacteriology, 54, 461.

Yeh, T. J., Anabtawi, I. N., Cornett, V. E., and Ellison, R. G. (1967). Circullation, 35, Suppl. No. 1, p. 77.

\title{
Biologically Active Cortisol in Plasma of Oestrogen-treated and Normal Subjects
}

\author{
C. W. BURKE,* M.A., M.R.C.P.
}

\begin{abstract}
Cummary : Biologically active (non-protein-bound) $S$ cortisol levels in the plasma of 13 women taking oral contraceptives and of 67 normal subjects were compared, using a new method-steady-state gel filtration. Both total and unbound cortisol levels in the 67 normal subjects showed a skew distribution, which was roughly lognormal.

Unbound cortisol levels in 11 of the oestrogen-treated women were in the normal range, but the median value was significantly increased in this group. Total plasma cortisol levels in the oestrogen-treated group were, as expected, increased threefold, and all were outside the normal range.
\end{abstract}

\section{Introduction}

The biological activity of the cortisol (hydrocortisone) circulating in the bloodstream is exerted by the $5-10 \%$ which is not bound to protein (Slaunwhite et al., 1962; Matsui and Plager, 1966). The total plasma cortisol level in man is increased by administration of oestrogen, due to a threefold-increase in the plasma concentration of the major cortisol-binding protein, corticosteroid-binding globulin (Sandberg and Slaunwhite, 1959; Mills et al., 1960; Doe et al., 1964). But it is less certain whether unbound, biologically active cortisol levels in plasma are also increased by the administration of oestrogen.

It would be predicted that unbound cortisol levels would be normal in oestrogen-treated subjects, for they show no clinical

* Senior Registrar, Department of Medicine, Royal Postgraduate Medical School, London W.12. evidence of cortisol excess ; moreover, their urinary cortisol excretion is within the normal range (Sandberg et al., 1967). Indeed, Mills et al. (1960) found that non-protein-bound cortisol levels "remained the same" during the administration of oestrogen. Others, however, have found increased unbound levels in oestrogen-treated subjects ; for example, a mean value of $4.2 \mu \mathrm{g} . / 100 \mathrm{ml}$. compared with normal mean of 0.9 $\mu \mathrm{g} . / 100 \mathrm{ml}$. (Doe et al., 1960); a mean value of $4.4 \mu \mathrm{g} . /$ $100 \mathrm{ml}$. compared with normal mean of $1.25 \mu \mathrm{g} . / 100 \mathrm{ml}$. (Plager et al., 1964 ; a mean value of $2.6 \mu \mathrm{g} . / 100 \mathrm{ml}$. compared with normal mean of $1.0 \mu \mathrm{g} . / 100 \mathrm{ml}$. (Murray, 1967). These raised values are surprising in view of the diminished production of cortisol found in oestrogen-treated subjects (Peterson et al., 1960 ; Layne et al., 1962). Some of these differences may be exaggerated by the technical difficulties in measuring unbound cortisol.

This paper compares values for unbound cortisol in normal and oestrogen-treated subjects, which were obtained by a new method, steady-state gel filtration. This method, which possesses high precision, does not appear to have been applied to measuring hormone-binding phenomena in the blood of man, and it would seem useful to apply it to cortisol-binding in oestrogen-treated subjects.

\section{Subjects and Methods}

Blood was drawn between 9.30 and 10 a.m. from 36 male and 31 female healthy clerical and medical staff, and from 13 women who had taken $0 \cdot 1 \mathrm{mg}$. of mestranol, combined with a progestogen, in the form of various oral contraceptive tablets for at least two menstrual cycles. All subjects were 